\title{
The Availability of Services and Facilities Provided for Students with Disabilities at Al al-Bayt University in Jordan from Their Own Perspective
}

\author{
Wael Alshurman
}

Akef Al-Khateeb

Al-Saree Ihsan

Special Education and Psychology Department, Faculty of Education, Al al-Bayt University, Jordan

DOI: https://doi.org/10.36941/ajis-2021-0108

\begin{abstract}
The study aims to examine the availability level of services and facilities provided for students with disabilities at Al Al-Bayt University from their own perceptions. Descriptive and analytical methodologies were used. Data was collected using a questionnaire consisting of (65) criteria distributed on (6) domains. Participants included all students with visual, hearing, and physical disabilities, with a total of (53) students from all faculties. All students receive support from the disability support division at the university. Results indicated that the availability of services and accommodations provided for students with disabilities were ranked respectively as follows: facilitations regarding information resources, social services, administrative facilitation, academic services and accommodations, physical accommodations, and finally library services and accommodations. The mean degree on the total score was $(M=1.81)$ which indicates a medium level. Also, results showed no statistically significant differences at $(\alpha=0.05)$ due to type of disability on all domains and on the total degree for the nature of services and accommodations provided. There were also no statistically significant differences at $(\alpha=0.05)$ due to the type of faculty on all domains and on the total degree for the nature of services and accommodations provided.
\end{abstract}

Keywords: Students with Disabilities, Services, Accommodations, AL Al- Bayt University, Jordan

\section{Introduction}

Nowadays, Special Education receives an unprecedented interest worldwide. This profession is concerned with the development of academic, social, and economic qualifications for students with disabilities. This is contributing to human development needed for developed and developing societies. It seeks to achieve the principles of equal opportunities, human rights, participation in community life, and social justice. Special Education has tremendous achievements in the past four decades, and it assisted people with disabilities to acquire skills that were considered unattainable in the past (Al-Khatib, 2014; Al-saree, Alshurman, \& Alshurfat, 2020).

Students with disabilities are part of the educational system at any university, therefore the university should meet all their needs and requirements beginning of their enrollment and admission at the university ending with their graduation to qualify them for future responsibilities. University 
has a responsibility in preparing students with disabilities academically and equipping them for the job market which reduces the burden on the country and society and thus limiting the social and psychological consequences of having a disability. Students with disabilities are a source of positive impact in the progress of societies and should play a role in development to keep pace with civilization and the enormous scientific and technological progress. Any university with large numbers of students with disabilities should provide access to education and training for all those students meeting their needs. Each student regardless of his/ her ability should be equipped with support and acceptance from the university's community, whether peers, faculty members, or administrators' staff (Altrams, 2001; Al-Khateeb, Alshurman, \& Al-Saree, 2020).

The effectiveness of private services and programs provided to students in educational institutions, whether schools or universities, is determined by measuring the extent to which objectives are measured and quality control which measured by the achievement of goals set (Alsalem \& Abu Doush, 2018). Therefore, the quality control in Special Education is measured through programs, services, and accommodations provided to individuals with disabilities. Achieving objectives set according to scales are already designed to assess these programs depending on the standards of services provided in these programs. In fact, there are particular standards of educational institutions and professional practices for those working in the field of disabilities. These include standards related to the knowledge in the foundations of educating students with disabilities, development of the characteristics of the learner, educational and individual differences, instructional strategies, learning environments, social interactions, language, planning for learning, evaluation, and standards related to the professional and ethical practices in teaching students with disabilities (Hallahan \& Kauffman, 2006; Wael, Ihsan, \& Kaur, 2020).

As a result of tremendous development in the field of Special Education, Jordan has witnessed significant progress in the provision of diagnostic, health, educational and social rehabilitation for people with disabilities (Saree \& Shurman, 2019). The Rights of Persons with Disabilities Act No. 31 of 2007 was issued (http://www.nrdc.homestead.com), and as a result, the Supreme Council for the Affairs of Persons with Disabilities was established with a response of policymaking being considered an umbrella for coordination among all agencies responsible for providing services. The law defined the role and competence of several ministries including higher education, directorate of education, social development, employment of health and medical services. In this article, we will focus on the role of the Ministry of Higher Education in providing opportunities for people with disabilities to facilitate their rights to educate each one of them in accordance with their abilities and potentialities. On top of that, preparing technical and administrative services qualified to work with various disability categories and releasing and implementing the National Strategy for people with disabilities are other goals of this study (http://www.mosd.gov.jo).

Modern trends confirm that the preparations carried out by authorities at Higher Education for the integration of students with disabilities at universities differ to some extent from other special education services. Therefore, it was necessary to involve specialists' attitudes toward services and accommodations necessary for the integration of students with disabilities at universities (Al-Wabili, 2001).

Similar to their peers, university students with disabilities encounter many problems. These refer to the nature, type, and severity of their disability. The main problems are related to using the library, conducting examinations, using special means and technologies as well as problems in adapting to university life. Movement and accessibility are also considered a barrier to students with disability. Students also face different challenges when communicating with staff and faculty members who lack knowledge about the characteristics and needs of students with disabilities or prober methods of offering them assistance. Students with disabilities face academic, social, psychological, and physical difficulties at the university in general. Barriers in the university environment and lack of awareness negatively affect their scientific capabilities (Wael, Ihsan, Kaur, 2020).

The pertinent literature is rich in similar studies. For instance, Dwiekat (2016) aimed to identify 
the availability of services provided to students with disabilities in Palestinian universities from the academic and administrative members' perspectives. Results extracted from the study showed that services provided include psychological, social, academic, administrative, and structural accommodations services in addition to services related to technology. Other results indicated the need to involve students with disabilities in methodological and extracurricular activities.

Similarly, Al-Adrah, (2016) examined the challenges facing students with disabilities at the University of Jordan in addition to identifying general characteristics of students. The study data was collected using a questionnaire. The study sample consisted of (81) students who were selected randomly. Results indicated that students with disabilities at the university suffer from many administrative difficulties in the registration procedures including the lack of academic guidance, studying difficulties and competition with colleagues, performance during examinations, difficulties incomprehension of the educational material, environmental facilitations, lack of participation in university activities, social difficulties related to a lecturer, lack of considerations for their circumstances, negative attitudes of peer students, and difficulty in getting in communicating with them.

Another study conducted by Al-Hadidi and Al-Zaboun (2013) aimed to assess the availability of library services provided to people with visual disabilities in Jordan comparing to international standards. The study sample consisted of (32) libraries of public and private universities. Results indicated a very weak level of international standards of library services for people with disabilities. Also, five dimensions had a very weak level of availability including library services, human resources and public relations, sources of information, and modern equipment and technology. Moreover, the library building had a very weak level of availability.

AL-Momani and Smadi (2012) aimed to review legislations and laws at the University of Jordan and their suitability for students with disabilities. The study focused on the laws adopted by the university related to acceptance procedures, student's housing, registration, library, public services, examinations, penalties, semester postponement, extracurricular activities, and technical support services. Results showed a very weak percentage for university legislative acts students with disabilities. The study recommended the need to review laws and regulations to meet the needs of students with disabilities.

In addition to what have been stated above, Hill (2012) conducted a study to evaluate library services available for students with disabilities through evaluating librarians on their level of information related to such services, resources provided by the library for those students in addition to adaptations and modifications offered by the library to serve them. The numbers of participants were (157) librarians. Results showed an acceptable level of knowledge on dealing with students with disabilities. Nevertheless, most of the information sources available by (93\%) were not appropriate for students with disabilities; (74\%) indicated that the library building is not accessible and hinder the movement of individuals with disabilities.

What is more, Moke and Love (2012) conducted a study to identify the experience of students with disabilities in using the internet. The study was conducted on (16) students. These were (12) females and (4) males. Eight tasks were investigated including electronic periodicals, using the internet, periodicals, and e-books due to the increased demand for electronic services. It was found that the students face difficulty in reading and acquiring information obtained from computers since the strategies followed did not take into account different disabilities. The study recommended the need for administrators to develop e-services provided to meet students' needs and reconsider strategies adopted by the university.

Al-Ayed et al., (2010) examined problems faced by students with disabilities at Taif University. The number of participants was 9 females and 8 males. Of them, (5) with physical disabilities, (3) with hearing disability, and (9) with visual disability. All of them were enrolled in education, arts, and administrative sciences faculties. A questionnaire that included 80 items was distributed to identify problems faced by those students. Results indicated economic problems, administrative problems, and psychological problems. The study also indicated that problems faced by those students do not 
differ by their academic level. In fact, there are no statistically significant differences in the problems related to specialties or type and severity of the disability. Moreover, males have a higher degree in the problems they face compared to females.

Al-Maegene et al., (2009) aimed to investigate the status of students with disability in higher education, universities, and institutions in the Gulf Cooperation Council (GCC) in terms of the numbers of students admitted, regulations and legislation governing their admission, services provided for them, plans for increasing the number of students admitted, and methods to improve services provided for them. The study revealed that the number of students with disabilities accepted in higher education institutions in the Gulf Cooperation Council was very small. In addition, it was found that the categories of disability integrated into higher education were limited to visual and hearing disabilities.

Another study was conducted by Al-khashrami (2008). It aimed at assessing the support services for students with disabilities at King Saud University in Saudi Arabia. 85 male and female students with disabilities have participated in the study. Results indicated that nearly $50 \%$ of the study sample believe that university buildings are not adapted to the needs of students with disabilities. On the other hand, social interaction with non-disabled colleagues, faculty, and administrators' staff was good concluding a positive indicator for the effectiveness of social integration. $(60 \%)$ of students with disabilities are not satisfied with teaching methods at the university. As for services provided for students with a disability, results indicated negative attitudes regarding the lack of coordination during students' examinations due to the low budget assigned for disability services and the lack of staff working with those students.

Additionally, Abu Mariam (2007) aimed to identify the needs of students with hearing disability at the University of Jordan. The study sample consisted of 56 students. Results indicated that students need academic guidance in addition to social and psychological needs. The need for verbal training and family support were also revealed. Results showed significant differences in the field of academic needs followed by social and psychological needs and the need for academic guidance due to faculty.

It is worth mentioning that the importance of this study is highlighted through students with disability experiences in Al-Al-Bayt University who lack information about provided services and accommodations which affected their academic and social success. In addition, informing policymakers at the university about the importance of improving those services to meet the needs of those students is of great importance too. Hence this study aims to answer the following main questions:

- What is the availability of services and accommodations provided to students with disabilities at Al-Al-Bayt University from students' perspectives?

- Do the services and accommodations provided to students with disabilities differ depending on the type of disability?

- Do the services and accommodations provided to students with disabilities differ by the type of faculty?

- Nevertheless, the authors acknowledge the following limitations:

- This study was limited to evaluating services and accommodations provided to students with disabilities at $\mathrm{Al}$ - Bayt University in Jordan.

- Results are determined through psychometric properties (validity and reliability) of the study tool and its comprehensiveness in covering services and accommodations provided to students with disabilities at the university.

- $\quad$ The time duration of this study is limited to the academic year 2020-2021.

\section{Methodology}

\subsection{Method of research}

This study is analytical and descriptive research that aims at describing the reality of services and accommodations provided for students with disabilities at Al - Bayt University in Jordan. 


\subsection{Study Population and Sample}

The population and the sample in this study include all students with physical, hearing, and visually disabled students enrolled at the scientific and humanitarian faculties of Al-Al-Bayt University amounting to (53) student; (35) males and 18 females receiving services from the Deanship of Student Affairs for the academic year 2020/2021; Table (1) shows the distribution of the study sample.

Table 1: Distribution of the study sample by disability, specialization, and gender

\begin{tabular}{lclccc}
\hline Disability category & Number & Specialization & Number & Gender & Number \\
\hline Visual & 14 & Scientific & 11 & Male & 35 \\
Motor and physical & 20 & Humanitarian & 42 & Female & 18 \\
Hearing & 19 & & 53 & \multicolumn{2}{c}{53} \\
Total & 53 & & \multicolumn{3}{c}{} \\
\hline
\end{tabular}

\section{Tool of Study}

\subsection{Tool preparing}

Tool of services and accommodations provided for students with disabilities at Al Al-Bayt University was prepared through reviewing the theoretical literature and previous studies related to the subject of the current study, such as: (Ma'agene, 2009), (Al-khashrami, 2008), (Dweikat, 2016), ( Al-Hadidi \& Al-Zaboun, 2013), (Eisenman, 2006 ) and ( Hill, 2012 ). After that the tool of study in its initial image was developed which is consisted of ( 6 ) main dimensions and ( 68 ) indicators; in accordance with the reviewer's opinions, the number of items decreased to ( 65 ) indicators distributed into ( 6 ) main dimensions; as shown in table ( 2 ). The validity of the study tool was investigated through content validity by (8) experienced reviewers in the field of special education, psychology, and counseling.

An agreement ratio of (87\%) among reviewers (seven out of eight) was achieved; some items were deleted, reformulated, or moved to other dimensions. The number of the main dimensions was (6) and the number of indicators was (65) as shown in Table (2). Also, the triple Likert scale was adopted to correct the study tool by giving each item a score of (available, moderately available, or unavailable) which are digitally scored as $(3,2,1)$, respectively. The following scale has been adopted to analyze the results: from $1.00-1.66$ is considered a low degree; from $1.67-2.33$ a moderate degree and from 2:34 - 3:00 a high degree. The total scale was calculated by using the following equation:

The category length $=\frac{\text { Upper limit- Minimum limit }}{3}=\frac{3-1}{3}=0.66$

Table 2: Dimensions and the number of indicators in each area

\begin{tabular}{lll}
\hline Number & Dimension: & Number of Indicators \\
\hline $\mathbf{1}$ & Physical Services and accommodations. & $\mathbf{1 2}$ indicators \\
$\mathbf{2}$ & Library Services and accommodations. & $\mathbf{1 2}$ indicators \\
$\mathbf{3}$ & Academic services and accommodations. & $\mathbf{1 3}$ indicators \\
$\mathbf{4}$ & Administrative services and accommodations. & $\mathbf{1 1}$ indicators \\
$\mathbf{5}$ & Social services and accommodations. & 10 indicators \\
$\mathbf{6}$ & Services and accommodations related to the sources of information. & 7 indicators \\
Total & & 65 indicators \\
\hline
\end{tabular}

The reliability of the Study Tool was investigated through the internal consistency by Cronbach's alpha coefficient as shown in Table (3). 
Table 3: The internal consistency coefficient Cronbach's alpha and the test-retest reliability of the dimensions and the total degree

\begin{tabular}{lcc}
\hline Dimensions & $\begin{array}{c}\text { Test-retest } \\
\text { Reliability }\end{array}$ & $\begin{array}{c}\text { Internal } \\
\text { Consistency }\end{array}$ \\
\hline Physical Services and accommodations. & 0.94 & 0.89 \\
Library Services and accommodations. & 0.91 & 0.86 \\
Academic services and accommodations. & 0.90 & 0.84 \\
Administrative services and accommodations. & 0.91 & 0.87 \\
Social services and accommodations. & 0.93 & 0.86 \\
Services and accommodations related to the sources of information. & 0.94 & 0.85 \\
Total degree & 0.93 & 0.92 \\
\hline
\end{tabular}

The internal consistency values according to Cronbach's alpha equation and test-retest reliability were arranged (0.84-0.94) that means that the values are appropriate for use in this study, Table (3).

\section{Results}

To answer the questions of the study, statistical analysis was carried out using SPSS. Frequencies, means, percentages, and standard deviations were measured. One-way analysis of variance (ANOVA) was also used. Means and standard deviations were calculated for the level of services and accommodations available for students with disabilities at $\mathrm{Al}$ al-Bayt University from their perspective; as shown in Table (4).

Table 4: Means and standard deviations for the level of services and accommodations available for students with disabilities at $\mathrm{Al}$ al-Bayt University from their perspective

\begin{tabular}{cclccc}
\hline \multicolumn{2}{l}{ Rank Number Dimension } & \multicolumn{2}{c}{ SMA } & $\begin{array}{c}\text { Standard } \\
\text { Deviation }\end{array}$ & $\begin{array}{c}\text { Degree of } \\
\text { Applicability }\end{array}$ \\
\hline 1 & 6 & Services and accommodations related to the sources of information & $\mathbf{1 . 9 4}$ & .427 & Medium \\
\hline 2 & 5 & Social services and accommodations & 1.90 & .326 & Medium \\
3 & 4 & Administrative services and accommodations & 1.86 & .345 & Medium \\
4 & 3 & Academic services and accommodations & 1.85 & .313 & Medium \\
5 & 1 & Physical Services and accommodations & 1.78 & .354 & Medium \\
6 & 2 & Library Services and accommodations & 1.59 & .2927 & Low \\
\hline
\end{tabular}

Table (4) shows that means have ranged between ( 1.59 - 1.94); services and accommodations related to the information resources was with the highest mean of (1.94); social services and accommodations came second with a mean of (1.90), administrative services and accommodations was ranked third with a mean of (1.86), academic services and accommodations followed with a mean of (1.85), physical services and accommodations came fifth with a mean of (1.78). Finally, library services and accommodations was ranked the least with a mean of (1.59); the mean for the total degree as a whole was (1.81).

As for services provided for students with disabilities and whether they vary according to the type of disability, means and standard deviations for services provided to students with disabilities were extracted according to the variable of the type of disability; as shown in Table No. (5). 
Table 5: Means and standard deviations for services provided for students with disabilities according to the type of disability

\begin{tabular}{|c|c|c|c|c|}
\hline Dimension & Categories & Number & SMA & $\begin{array}{l}\text { Standard } \\
\text { Deviation }\end{array}$ \\
\hline \multirow{4}{*}{ Physical Services and accommodations } & Visual & 14 & 1.77 & .338 \\
\hline & Hearing & 19 & 1.84 & .397 \\
\hline & Physical and motor & 20 & 1.74 & .331 \\
\hline & Total & 53 & 1.78 & .354 \\
\hline \multirow{4}{*}{ Library Services and accommodations } & Visual & 14 & 1,548 & .2483 \\
\hline & Hearing & 19 & 1.680 & $\cdot 3771$ \\
\hline & Physical and motor & 20 & 1.554 & .2168 \\
\hline & Total & 53 & 1.597 & .2927 \\
\hline \multirow{3}{*}{ Academic services and accommodations } & Visual & 14 & 1.89 & .271 \\
\hline & Hearing & 19 & 1.87 & .276 \\
\hline & Physical and motor & 20 & 1.82 & .380 \\
\hline & Total & 53 & 1.85 & .313 \\
\hline \multirow{4}{*}{ Administrative services and accommodations } & Visual & 14 & 1.86 & .266 \\
\hline & Hearing & 19 & 1.91 & .343 \\
\hline & Physical and motor & 20 & 1.81 & .402 \\
\hline & Total & 53 & 1.86 & .345 \\
\hline \multirow{4}{*}{ Social services and accommodations } & Visual & 14 & 1.87 & .284 \\
\hline & Hearing & 19 & 1.92 & .280 \\
\hline & Physical and motor & 20 & 1.91 & .401 \\
\hline & Total & 53 & 1.90 & .326 \\
\hline \multirow{4}{*}{ Services and accommodations related to information resources } & Visual & 14 & 1.90 & .394 \\
\hline & Hearing & 19 & 1.98 & .444 \\
\hline & Physical and motor & 20 & 1.93 & .451 \\
\hline & Total & 53 & 1.94 & .427 \\
\hline \multirow[t]{4}{*}{ Total degree } & Visual & 14 & 1.80 & .184 \\
\hline & Hearing & 19 & 1.86 & .276 \\
\hline & Physical and motor & 20 & 1.78 & .244 \\
\hline & Total & 53 & 1.76 & .481 \\
\hline
\end{tabular}

Table (5) shows a virtual variance in means and standard deviations for services provided to students with disabilities related to the different categories of disability. To indicate the significance of the statistical differences between means, a one-way analysis of variance was used as shown in Table No. (6).

Table 6: Variance analysis of the impact of disability type on services provided to students with disabilities

\begin{tabular}{|c|c|c|c|c|c|c|}
\hline & Source & $\begin{array}{l}\text { Sum of } \\
\text { Squares }\end{array}$ & $\begin{array}{l}\text { Degrees of } \\
\text { Freedom }\end{array}$ & $\begin{array}{l}\text { Average } \\
\text { Squares }\end{array}$ & $\begin{array}{c}\text { P- } \\
\text { Value } \\
\end{array}$ & $\begin{array}{c}\text { Statistical } \\
\text { Significance }\end{array}$ \\
\hline \multirow{3}{*}{$\begin{array}{l}\text { Physical Services and accommodations } \\
\text { Library Services and accommodations }\end{array}$} & Among groups & .101 & 2 & .051 & .395 & .676 \\
\hline & Within groups & 6.416 & 50 & .128 & & \\
\hline & Total & 6.517 & 52 & & & \\
\hline \multirow{3}{*}{ Academic services and accommodations } & Among groups & .201 & 2 & .101 & 1.182 & .315 \\
\hline & Within groups & 4.254 & 50 & .085 & & \\
\hline & Total & 4.455 & 52 & & & \\
\hline \multirow{4}{*}{$\begin{array}{l}\text { Administrative services and } \\
\text { accommodations } \\
\text { Social services and accommodations }\end{array}$} & Among groups & .045 & 2 & .023 & .224 & .800 \\
\hline & Within groups & 5.063 & 50 & .101 & & \\
\hline & Total & 5.108 & 52 & & & \\
\hline & Among groups & .089 & 2 & .044 & .364 & .697 \\
\hline \multirow{2}{*}{$\begin{array}{l}\text { Services and accommodations on the } \\
\text { sources of information }\end{array}$} & Within groups & 6.103 & 50 & .122 & & \\
\hline & Total & 6.192 & 52 & & & \\
\hline
\end{tabular}




\begin{tabular}{|c|c|c|c|c|c|c|}
\hline \multirow{3}{*}{$\begin{array}{l}\text { Total degree } \\
\text { Physical Services and accommodations }\end{array}$} & Among groups & .021 & 2 & .011 & .096 & .909 \\
\hline & Within groups & $5 \cdot 518$ & 50 & .110 & & \\
\hline & Total & $5 \cdot 539$ & 52 & & & \\
\hline \multirow{3}{*}{ Library Services and accommodations } & Among groups & .066 & 2 & .033 & .174 & .840 \\
\hline & Within groups & 9.421 & 50 & .188 & & \\
\hline & Total & $9 \cdot 487$ & 52 & & & \\
\hline \multirow{3}{*}{$\begin{array}{l}\text { Academic services and accommodations } \\
\text { Administrative services and } \\
\text { accommodations }\end{array}$} & Among groups & .059 & 2 & .029 & .497 & .611 \\
\hline & Within groups & 2.945 & 50 & .059 & & \\
\hline & Total & 3.004 & 52 & & & \\
\hline
\end{tabular}

Table (6) shows that there are no statistically significant differences at $(\alpha=0.05)$ caused by the type of disability in all dimensions and the total degree.

Related to the services provided for students with disabilities and whether it varies depending on the type of the faculty, means and standard deviations were calculated and, "T" Test was used to investigate significant differences as shown in Table No. (7).

Table 7: Means, standard deviations, and T-test for the effect of faculty type on services provided for students with disabilities

\begin{tabular}{|c|c|c|c|c|c|c|c|}
\hline Dimension & Faculty type & Number & SMA & $\begin{array}{l}\text { Standard } \\
\text { Deviation }\end{array}$ & $\begin{array}{c}\text { "T" } \\
\text { Value }\end{array}$ & $\begin{array}{c}\text { Degrees } \\
\text { ofFreedom }\end{array}$ & $\begin{array}{c}\text { Statistical } \\
\text { Significance }\end{array}$ \\
\hline \multirow{2}{*}{$\begin{array}{l}\text { Physical Services and } \\
\text { accommodations }\end{array}$} & Scientific & 11 & 1.91 & .525 & 1.354 & 51 & .182 \\
\hline & Humanitarian & 42 & 1.75 & .294 & & & \\
\hline \multirow{2}{*}{ Library Services and accommodations } & Scientific & 11 & 1.81 & .283 & 1.021 & 51 & .704 \\
\hline & Humanitarian & 42 & 1.54 & .269 & & & \\
\hline \multirow{4}{*}{$\begin{array}{l}\text { Academic services and } \\
\text { accommodations } \\
\text { Administrative services and } \\
\text { accommodations }\end{array}$} & Scientific & 11 & 1.89 & .314 & .392 & 51 & .697 \\
\hline & Humanitarian & 42 & 1.85 & .316 & & & \\
\hline & Scientific & 11 & 1.89 & .439 & .337 & 51 & .737 \\
\hline & Humanitarian & 42 & 1.85 & .322 & & & \\
\hline \multirow{2}{*}{ Social services and accommodations } & Scientific & 11 & 1.77 & .276 & 1.514 & 51 & .136 \\
\hline & Humanitarian & 42 & 1.94 & .333 & & & \\
\hline \multirow{2}{*}{$\begin{array}{l}\text { Services and accommodations on the } \\
\text { sources of information }\end{array}$} & Scientific & 11 & 2.03 & $\begin{array}{l}.5 \\
06\end{array}$ & .741 & 51 & .462 \\
\hline & Humanitarian & 42 & 1.92 & .408 & & & \\
\hline \multirow{2}{*}{ Total Degree } & Scientific & 11 & 1.88 & .323 & 1.013 & 51 & .316 \\
\hline & Humanitarian & 42 & 1.79 & .215 & & & \\
\hline
\end{tabular}

Table No. (7) Shows no statistically significant differences at $(\alpha=0.05)$ due to the impact of faculty type in all dimensions and the total degree.

\section{Discussion}

Results indicate a medium level of the total score, table (4). It is useful here to note that a medium level does not indicate that the level of services and accommodations provided to those students was not good. However, it states that there are some services are available at an acceptable level while another is available at a low degree; the possibility of developing such services will be discussed later. The previous result can be explained by the lack of standards, regulations, and instructions for services and accommodations needed by students with disabilities at Al-Al-Bayt University that are based on the accreditation criteria and quality control in the field of Special Education. This may discourage administrative, technical, and academic staff providing these services and accommodations from providing much attention to the issue of quality control and leading to less monitoring and evaluation by the university. Few qualified and trained administrative and technical staff is available in dealing with students with disabilities at the university. There was also a lack of 
following- up by the relevant authorities to ensure services quality, effectiveness, and availability through evaluating such services and accommodations regularly, and benefitting from the results of the evaluation in developing such services and accommodations.

It is worth noting that, the researchers need to set stable and agreed-upon standards for the quality of services and accommodations in terms of the clarity of the vision, objectives, planning, organization, monitoring, and accountability in cooperation with the Department of Quality and Accreditation at the university, the Faculty of Education, the Department of Psychology and Special Education, and the Deanship of Students Affairs. This can be achieved through the division of the unit responsible for supporting students with disability, the division of psychological counseling, and the mental health in order to work on the establishment of special services center for students with disabilities at the university.

In this regard, there is a need to review legislation, laws, and regulations at the university and their suitability for students with disabilities. Results of this study are consistent with Al-Momani and Al-Smadi (2012) and Al-Adrah (2016) which recommended the need to review laws and regulations to meet the needs of students by specialized committees. Results of this study are also consistent with Moke and Love (2012) which recommended the need for administrators to pay attention to developing electronic services provided for students and recognizing different strategies followed by the university. Also, there is a clear deficiency in the provision of construction and various accommodations that suit students with disabilities at the university. Students with a disability stated that university buildings are not adapted to their needs and that it lacks elements of public safety in the classroom and its equipment in addition to other public facilities such as restaurants and bathrooms, and in providing elevators and escalators. Furthermore, the majority of students see that no suitable transportations are suiting their disabilities while moving between buildings inside the university, no signboards designed and placed in a way that takes into account clarity and simplicity to help them move, and no suitable internal housing. That is consistent with (Aladrah, 2016; AlKhashrami, 2008; Dweikat, 2016) which asserted that students with disabilities have confirmed that university buildings and accommodations offered by the university are unprepared for meeting the needs of students with disabilities. In addition, the findings of this study are in line with Al-Ayed et al., (2010). It is so in the dimension of lacking adequate transportations and communications appropriate for students with disability.

In this situation, we can ascribe this to the low level of international standards available for library services and accommodations provided to students with disabilities at Al-Al-Bayt University. The previous point is consistent with the results of Al-Hadidi and Al-Zaboun (2013) and Ijadunol et al., (2019). Their studies indicated very weak international standards for library services for people with disabilities. Also, there is the lack of care in appointing people with experience to deal with all students with disabilities at the university, the lack of training opportunities for librarians to deal with students with disabilities, the obvious shortcomings in the development of electronic services, the provision of support materials and techniques, e-books, magnified prints or Braille printings, etc. These problems are due to the lack of necessary financial resources allocated for the implementation of these standards at Al - Al-Bayt University and the inadequacy of the university library building to the codes suitable for students with disabilities. The above-mentioned point is in line with the findings of Hill (2012) and Moke and love (2012). They found that the library building is not suitable for students with disabilities. However, the low level of library services and accommodations are available for students with disabilities. Also, they found that the provision of library services and accommodations for students with disabilities are not a priority of the national strategy for people with disabilities that is issued by the Supreme Council for the Affairs of Persons with Disabilities (2010-2015). Furthermore, the Supreme Council for the Affairs of Persons with Disabilities did not adopt any specific criteria of building adaptation to accommodate all students with disabilities. In fact, nearly $50 \%$ of students with disabilities are satisfied with services provided to them by the administrative staff. Accordingly, students believe that the university administrators understand their needs and listen to their problems, and also facilitates their admission and registration by allocating a 
specific day for registration. Deanship of Student Affairs through the support unit for students with disability work hard to provide a range of educational, professional, psychological, social, and recreational services. For example, in the university, there is a lab supervisor to help blind students, a special education specialist, a psychologist, teachers, and sign language translators. The deanship also follows - up for students with disabilities on their credit hours by (90\%) of undergraduate and graduate studies. Happily, the previous results are consistent with the results revealed by AlKhashrami (2008). It was indicated that nearly half of the sample had a positive relationship with faculties' members and administrative staff, which is, indeed, considered a positive indicator for effective social integration. Simultaneously, the above-stated findings are not correspondent with the findings obtained from Al-Ayed et al., (2010); Dweikat (2016); and Al-Dura (2016). Their studies revealed that most of the problems faced by the disabled at universities are related to problems in the administrative aspect. In this dimension, we can notice a deficiency in the role of the media department in dealing with issues of students with a disability, especially regarding social and societal integration and students' rights to education. Also, the study showed that students with disabilities do not participate in scientific, mathematical, social, and cultural extracurricular activities through clubs available at the university. However, the dimension lacks participation between students with disabilities and public activities at the university whether cultural, social, or physical. Accordingly, the weakness of this important interactive aspect leads to more affiliation at the university. Supporting the above results, it was noted that the previous findings are consistent with Dweikat (2016), which confirmed that there are shortcomings in the field of media in highlighting issues of those with disabilities. Moreover, the previous findings are consistent with the results of AlKhashrami (2008), which indicated that the relation between students with disabilities and employees at the university has a positivity where the faculty members avoid using negative terms of disability. Students agreed that faculty staff deal with disabled students in the same way as nondisabled peers, and that there is a positive relationship between students with disabilities and non disabled colleagues at the university. Hence, the researcher believes that the proper interaction with students should be a reality which is the goal sought for at campus. This may be attributed to some wrong prevailing beliefs in the community about people with disabilities and their abilities, needs, and problems that limit communicating with them. It is worth noting that, sources of information are considered a crucial axis in deepening affiliation to the university; it is evident here that students benefit with a medium degree from information provided by the university webpage. Information about different departments and faculties at the university, faculty members, students without disabilities, and students support unit at the Deanship of Student Affairs. Students with a disability find that the university's newspaper has shortcomings in the provision of news and information needed by students with disabilities related to services and accommodations offered by the university. Interestingly, this result is inconsistent with Dweikat (2016); Al-Khashrami (2008), and AlHadidi and Al-Zaboun (2013) studies. They confirmed that information recourses had a low level of availability. Also, there are no statistically significant differences at $(\alpha=0.05)$ caused by the type of disability in all dimensions and the total degree, Table (6). This result was limited due to the absence of some disability categories such as learning difficulties, multiple disabilities, health disabilities, mental disabilities, and autism disorders ... etc. The majority of participants at the university have similar difficulties in movement, getting access, and the nature of services and accommodations provided for them, which led to similar problems regarding services and accommodations. Therefore, results were consistent with the reality of students with disabilities in Al al-Bayt University. In addition, this result is consistent with Al-Ayed et al., (2010) and Al-Maegene et al., (2009) which confirmed that the number of students is significantly concentrated in certain groups of disabilities, hearing, visual and physical disabilities and that there is a lack in participating for other disabilities at universities and institutions of higher education in the Gulf Cooperation Council countries (GCC). Results of this study are inconsistent with Al-adrah (2016) and Alsalem and Abu Doush (2018) which showed a statistically significant difference in environmental differences that were in favor of those with a physical disability who faced more difficulties in general in terms of 
buildings and accommodations, walkways, etc. Also, there are no statistically significant differences at $(\alpha=0.05)$ due to the impact of faculty type in all dimensions and the total degree, Table ( 7$)$. The previous point can be interpreted with the fact that students with disabilities agree on the availability of all necessary university services and accommodations at all faculties and departments due to its importance for students with disabilities at all faculties. Results of the study are consistent with Abu Maryam (2007) who showed no statistically significant differences in the field of academic, social, and psychological needs and the need for academic guidance related to faculty type. The previous study is also consistent with Al-Adrah (2016) and Alsalem and Abu Doush (2018) which showed no statistically significant differences in difficulties faced by students with disabilities attributable to faculty type. Therefore, students in scientific and humanitarian faculties are both facing difficulties in general, although those enrolled in scientific colleges are more likely to face difficulties when using laboratories.

\section{Conclusion}

In the light of the above discussion, the researchers encourage the university to form a committee in collaboration with the psychology and special education departments to improve services and accommodations for students with disabilities. The Ministry of Higher Education's systems could establish a service center for students with disabilities in Jordan's public and private universities providing training and qualified staff to deal with students with disability and to ensure the necessary tools for the success of the integration process in coordinate between the university and the relevant authorities represented by the Supreme Council for the Affairs of Persons with Disabilities, the Ministry of Higher Education, the Ministry of Education, the Ministry of Development and other private actors related to people with disabilities from the local community institutions. Additionally, establishing cooperation and exchange with Arab and international universities may offer advanced services and accommodations for students with disabilities in this area.

\section{References}

Abu Maryam, Annan (2007). The needs of students with hearing disabilities hearing at the Jordanian Universities and colleges, Unpublished Master Thesis, the University of Jordan, Amman, Jordan.

Ak-Khatib, Ahmad and Al-Khatib, Rdah (2010). Accreditation and control quality at the Arab Universities (a proposed model). Irbid: the modern world of books.

Al-Khateeb, A. A., Alshurman, W. M., \& Ali Al-Saree, I. I. (2020). Emotional Intelligence Levels among Hearingimpaired and Visually Impaired Students in Jordan. Journal of Education and E-Learning Research, 7(4), 395406. https://doi.org/10.20448/journal.509.2020.74.395.406

Al-Adrah, Ibrahim (2016). Challenges that students with disabilities at the University of Jordan's face, a field study, a published study, Derasat Journal, Humanities, and Social Sciences Studies, University of Jordan, Volume 43, Appendix (5), pp 3013-2032.

Al-Ayed, Wasef, Abdullah, Jaber Asfour, Qais, Altheini, Awad (2010). Problems faced by students with special needs at the University of Taif, Saudi Arabia.

Al-Hadidi Mona, the Al-Zaboun, Eman (2013). Evaluation of library services provided to people with visual disabilities in light of the international standards. The University of Jordan, the Journal of Educational Sciences, Folder 9, Number 4, pp. 377-388, Amman, Jordan.

Al-jadiri, Adnan and Abu Helo, Yagoub. (2009). Methodological Foundations and statistical uses in the educational and humanities sciences. Amman: Esra house for publication and distribution.

Al-Khashrami, Sahar (2008). Assessment of the support services of students with special needs at King Saud University, Saudi Arabia. Taken fromwww.alrigadh.com/2008/o8/11/articale 36644. HTML

Al-Khateeb, Akef (2014). Quality control and certification in special education, a proposed model for the development of programs and services for people with autism and mental retardation disorder. The modern world of books for publication and distribution, Irbid. Jordan. 
Al-Momani, Fawaz, Al-Smadi, Fayez and Al-Momani, Insaf ( 2013). university Legislation university and its suitability to the needs of students with special needs: Analytical study of the university legislations, published paper, Journal of educational and psychological studies, University of Sultan Qaboos, Volume (7) number (1), pp. 64-76.

Alsalem, G. \& Abu Doush, I. (2018). Access education: what is needed to have accessible higher education for students with disabilities in Jordan?. International Journal of Special Education, 33(3), 541-561.

Al-Saree, I. I. A., Alshurman, W. M., \& Alshurfat, S. S. (2020). The Effectiveness of Supervision in Solving Problems Facing Teachers of Students with Autism Spectrum Disorder in Jordan. Journal of Education and E-Learning Research, 7(3), 314-322. https://doi.org/10.20448/journal.509.2020.73.314.322

Altrams, Saeed Mohammed (2012). Special categories: characteristics and social and educational methods of care. v. 4, publications of the Faculty of Education, Al - Azhar University, Cairo.

Al-Wabili, Abdullah (2001). The nature of the accommodations, services, and programs that should be met by the private higher education institutions for students of special categories as seen by the academic body of the special education, a study presented at a symposium of the National Higher Education, Faculty of Education, King Saud University, Riyadh.

Dweikat, Fakhri (2016). The reality of the services provided to students with special needs in the Palestinian universities, from the viewpoint of the members of the faculty and administration. A published Research, Journal of Educational and Psychological Studies. Quds Open University, Palestine. Volume 4, Issue (16), (p . 223-252).

Hallahan, D. \& Kauffman, j. (2006). Exceptional Learners: Introduction to special education (11 ${ }^{\text {th }}$ Ed.)New Jersey: Prentice-Hall.

Halle E Eisenman. (2005). A Study of the Services and Equipment Provided to disabled Patrons at the University of North Carolina at Chapel HillLibaries.A Master, s Paper for the M.S.in L.S degree.November,.p48

Hill, R. (2012) strengths and opportunities: school libraries serving students with special needs in central new york state, school library libraries, 34 (6), 90-93.

Ijadunol, M., Ojo, T., Akintan, F., Adeyemo, A., Afolayan, A. \& Akanji, O. (2019). Engendering a cognitive environment for university students with physical disabilities: assessing the availability of assistive facilities in Nigeria. Disability \& Rehabilitation.

Maegeni, Osama, Althbiti, Awad, Al-Khuraiji, Fatima, Al-Kaddoumi, Mohammed and Huwaidi, Mohammed (2009). The reality of students with special needs in the universities and higher education institutions in the countries of the Arab Gulf Cooperation Council, the Cooperation Council for the Arab Gulf States, the Secretariat.

Mock, Martha and Love, Kristen, (2012), One State's Initiative to increase Access to Higher Education for People with intellectual disabilities, Journal of Policy and Practice in Intellectual Disabilities, 9(4): 289-297.

Mosey, S. (2007). The inclusive libraries initiative: enhancing the access of persons with developmental disabilities information and communication technology. The developmental disabilities bulletin, 35 (1), 56-71.

Saree, Ihsan \& Shurman, Wael. (2019). The Extent of Teachers' Knowledge of Autism Spectrum Disorder for the Required Tasks and Responsibilities Related to Scientific Qualification and Years of Experience Variables. International Journal of Learning, Teaching and Educational Research. 18. 203-219. 10.26803/ijlter.18.10.13

The Supreme Council for the Affairs of Persons with Disabilities (2010-2015). National Strategy for Persons with Disabilities, Amman, Jordan.

The Supreme Council for the Affairs of Persons with Disabilities, the Rights of Persons with Disabilities Act, Law No. (31) for the year (2007), Amman, Jordan

Tudor, G. (2007). "The Study Problems of Students with disabilities in the Open University." Teaching at a Distance No. 9. Open University, pp. 43-49.

Wael Mohammad Alshurman, Ihsan Igdifan Ali Al-Saree, and Kaur Amreet. (2020). The Role of Assistive Technology in Success of the Individual Education Program for Disabled Students in Jordan. International Journal of Advanced Science and Technology, 29(7s), 825 - 837. Retrieved from http://sersc.org/journals/ index.php/IJAST/article/view/9989

\section{Websites}

http://www.mosd.gov.jo

www.nrdc.homestead.com 